\title{
NUMERICAL STUDIES OF NATURAL CONVECTION IN A SQUARE CAVITY
}

\author{
Viviana Cocco Mariani ${ }^{\mathrm{a}}$, \\ and Ivan Moura Belo \\ ${ }^{a}$ Pontifícia Universidade Católica do Paraná \\ Departamento de Engenharia Mecânica \\ Bairro Prado Velho \\ CP. 81611-970, Curitiba, Paraná, Brasil \\ viviana.mariani@pucpr.br \\ ${ }^{\mathrm{b}}$ Pontifícia Universidade Católica do Paraná \\ Departamento de Engenharia Mecânica \\ CP. 81611-970, Curitiba, Paraná, Brasil \\ ivan.belo@pucpr.br
}

\begin{abstract}
In the present work a numeric study of thermal and fluid dynamics behavior of natural air convection in a bi-dimensional square cavity is presented, in a laminar flow. The square cavity has two walls heated with different temperatures and two isolated walls, the Boussinesq approximation is used and a constant Prandtl number. The Finite Volume Method is used for the discretization of flow equations. The staggered load of variables is adopted and Power-Law and SIMPLE models are used. The numeric simulation is made up of several Rayleigh numbers, $10^{4} R a 10^{6}$, and the results of average Nusselt numbers are compared to values obtained in the literature. Flow and isotherm lines are presented and analyzed. The numerical results presented here in this work agree with the ones available in the literature and can be used by researchers who work in the convection problem numeric simulation area.
\end{abstract}

Keywords: natural convection, square cavity, Finite Volume Method

\section{NOMENCLATURE}

$\overline{N u}$

$N u_{x}$

$c_{p} \quad$ fluid specific heat at constant pressure, $\mathrm{J} /(\mathrm{kg} . \mathrm{K})$

$D_{h} \quad$ hydraulic diameter, $\mathrm{m}$

g gravity acceleration, $\mathrm{m} / \mathrm{s}^{2}$

$H$ height of cavity, $\mathrm{m}$

$k \quad$ thermal conductivity, W/m.K

$L \quad$ length of cavity, $\mathrm{m}$

$p \quad$ pressure, $\mathrm{N} / \mathrm{m}^{2}$

$P \quad$ dimensionless pressure

$\mathrm{Pr} \quad$ Prandtl number

$R \quad$ residue

$R a \quad$ Rayleigh number

$T \quad$ temperature, $\mathrm{K}$

$u, v \quad$ velocity components, $\mathrm{m} / \mathrm{s}$

$U, V \quad$ dimensionless velocity components

$x, y, z \quad$ cartesian coordinates, $\mathrm{m}$

$X, Y, Z$ dimensionless cartesian coordinates

\section{Greek symbols}

$\alpha \quad$ thermal diffusivity, $\mathrm{m}^{2} / \mathrm{s}$

$\beta \quad$ thermal expansion coefficient

$\theta \quad$ dimensionless temperature

$\mu \quad$ absolute viscosity, N.s $/ \mathrm{m}^{2}$

$v \quad$ kinematic viscosity, $\mathrm{m}^{2} / \mathrm{s}$

$\rho$ density, $\mathrm{kg} / \mathrm{m}^{3}$

$\psi \quad$ stream function

\section{Subscripts}

$\begin{array}{ll}C & \text { cold wall } \\ H & \text { hot wall } \\ \max & \text { maximum value }\end{array}$

\section{INTRODUCTION}

The quality of air in confined environments has an extensive applicability, it can be highlight the study of air in biological laboratories, pharmaceutical production units, production of electronic equipment, nuclear reactor operation, environment planning and building, solar energy collectors, etc. Natural convection in closed environments has been experimentally and numerically, extensively studied, works of Davis (1983), Ostrach (1988), Hortmann et al. (1990), Le Quéré (1991) and Bravo et al. (2000), Ding et al. (2004) who studied numerically closed square cavities with two adiabatic walls and two heated ones for different Rayleigh numbers are mentioned. Studies in closed rectangular cavities with heated walls, in one or both sides, were conducted by Anderson and Lauriat (1986).

Aydin et al. (1997) have investigated the flow in square cavities which were heated on one of the sides and cooled on the top. The air natural convection in a cubic tridimensional geometry differently heated on the two vertical walls was studied by Peng et al. (2003). Doescher et al. (2003) have analyzed the flow of a fluid in bidimensional cavities where the boundaries are level 0.1 and 2 Koch pre-fractals. For level 0 they have reproduced the same results obtained in the literature, for the other levels fluctuations were detected for $R e>4000$. Corcione (2003) has studied numerically the natural convection in a permanent regimen in closed rectangular bi-dimensional domains, where the inferior wall was heated and the superior one was cooled and different boundary conditions were investigated for lateral walls. Several simulations were performed changing the length of cavities and the Rayleigh number.

The fluid dynamic behavior of air in confined environments with presence of heat generation sources has been studied, mainly for the concern of industries in improving refrigeration of electronic components. Chu et al. (1976) have numerically studied an environment with a 
heat source situated on a vertical adiabatic wall, Oh et al. (1997) have studied a square cavity with a heat generation input source inside it and occupying $25 \%$ of the cavity volume. Reinehr et al. (2000) have studied cavities with geometric relations ranging between $1 \mathrm{H} / \mathrm{L} \quad 4$ with a heat source inserted in one of the vertical walls.

The present work investigates heat transfer by natural convection inside a closed bi-dimensional square cavity, in a permanent laminar flow. The cavity has isolated horizontal walls and vertical walls heated at different temperatures, i. e., the left vertical wall is cooled at a certain temperature $\left(T_{C}\right)$ and the right vertical wall is heated at a certain temperature $\left(T_{H}\right)$. The numeric simulation is performed by different Rayleigh numbers, $i$. e., $10^{4} R a 10^{6}$. The influence of the Rayleigh number on flow patterns is analyzed and discussed through temperature distribution, stream flow and the average Nusselt number, compared to values obtained in the literature.

The Boussinesq approximation is used and the Prandtl number is kept constant. The governing equations are solved using Finite Volume Method described by Patankar (1980). The staggered load of variables is adopted and the Power-Law and SIMPLE models are used.

\section{MATHEMATICAL MODEL}

To model the studied flow the Navier-Stokes equations and energy conservation are used, some simplifications are adopted: laminar flow, Newtonian incompressible fluid, bi-dimensional system, permanent regime, all fluid properties, $\rho, \mu, k$ and $c_{p}$ are considered constant, except for vertical direction density where the Boussinesq approximation is assumed and in the energy conservation equation, compressibility effects and viscous dissipation are assumed to be negligible. The following dimensionless governing equations are used,

$$
\begin{gathered}
X=x / H ; \quad Y=y / H ; \quad U=\frac{u}{(\alpha / H)} \\
V=\frac{v}{(\alpha / H)} P=\frac{\left(p-p_{0}\right) H^{2}}{\rho \alpha^{2}} \theta=\frac{T-T_{C}}{T_{H}-T_{C}}
\end{gathered}
$$

where, $X$ and $Y$ are the horizontal and vertical coordinates, respectively, $U$ and $V$ are horizontal and vertical velocity components, respectively, $\theta$ is temperature, $H$ is cavity height which is the characteristic dimension of the geometry studied in the present work, $v=\mu / \rho$ is kinematic viscosity, $u$ and $v$ are the velocity components in directions $x$ and $y, T$ is temperature, $T_{H}$ is the hot temperature prescribed for the right vertical wall and $T_{C}$ is the cold temperature prescribed for the left vertical wall. Thus, the dimensionless equations governing flow are,

$$
\begin{gathered}
\frac{\partial(U)}{\partial X}+\frac{\partial(V)}{\partial Y}=0 \\
\frac{\partial(U U)}{\partial X}+\frac{\partial(V U)}{\partial Y}=-\frac{\partial P}{\partial X}+\operatorname{Pr} \nabla^{2} U \\
\frac{\partial(U V)}{\partial X}+\frac{\partial(V V)}{\partial Y}=-\frac{\partial P}{\partial Y}+\operatorname{Pr} \nabla^{2} V+\operatorname{Ra} \operatorname{Pr}\left(\theta-\theta_{0}\right)
\end{gathered}
$$

$$
\frac{\partial(U \theta)}{\partial X}+\frac{\partial(V \theta)}{\partial Y}=\nabla^{2} \theta
$$

where dimensionless Prandtl $(P r)$ and Rayleigh $(R a)$ numbers are, respectively,

$\operatorname{Pr}=\frac{\mu}{\rho \alpha}$ and $R a=\frac{g \beta\left(T_{H}-T_{C}\right) H^{3} \operatorname{Pr}}{v^{2}}$

where $\alpha=k \rho / c_{p}$ is thermal diffusivity, $\rho$ is fluid density, $\mu$ is absolute viscosity, $\beta$ is thermal expansion coefficient, $k$ is thermal conductivity, $c_{p}$ is the fluid specific heat and $g$ is gravity acceleration.

The domain of computation used in the present work is shown in Fig. 1, it is a bi-dimensional square cavity with length $L$.

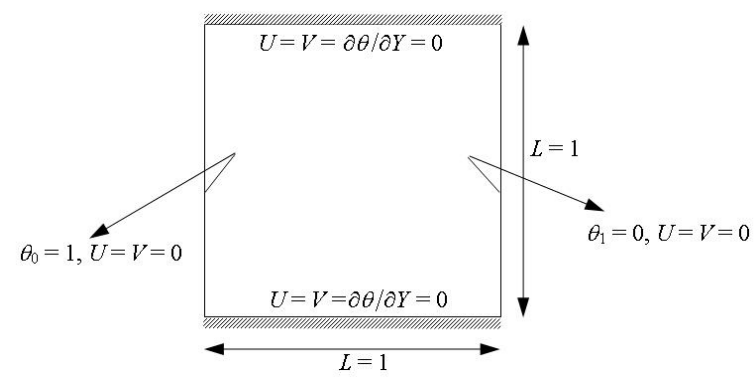

Figure 1. Geometry of the studied square cavity

The initial assumed conditions are $U=V=0$ e $\theta=$ 0.5 for all domain, or better, $0 \leq X, Y \leq 1$. The boundary conditions are: (a) $U=V=0$ (non slipping conditions) on all cavity walls; (b) $\theta=0$ at $X=0$ (on the left vertical wall); (c) $\theta=1$ at $X=1$ (on the right vertical wall) and $\frac{\partial \theta}{\partial Y}=0(\mathrm{~d})$ at $Y=0$ and $Y=1$.

The differential equations, represented by Eqs. (3) to (6), together with the respective boundary conditions, are solved using the Finite Volume Method (FVM), described in detail by Patankar (1980). In this method the solution domain is divided in small finite control volumes. The differential equations are integrated in each one of these control volumes. From this integration there results an algebraic equation that, when solved, simultaneously or separately, supplies the velocity and pressure components. The Power-law interpolation is adopted to estimate the diffusive and convective terms. For the coupling pressurevelocity the SIMPLE (Semi IMPlicit Linked Equations) algorithm is used.

The descriptive equations are solved iteratively, using the line by line method known as Thomas algorithm or TDMA (TriDiagonal Matrix Algorithm). Subrelaxation is used to accelerate convergence (Patankar, 1980; Maliska, 1995). The solution domain is covered by a uniform mesh made up of $40 \times 40$ and $80 \times 80$ control volumes, which is used in all numerical simulations. The staggered load of variables is used. The numeric solution is considered converging when the absolute maximum value of mass conservation is lower than $10^{-6}$. After the convergence is obtained the average Nusselt number on the heated vertical wall is calculated as,

$$
\overline{N u}=\frac{D h}{\left(\theta_{1}-\theta_{0}\right)} \int_{0}^{1} N u_{x} d Y
$$


where $D h=4$ Area/Perimeter is the hydraulic diameter and $N u_{x}=-(\partial \theta / \partial X)_{X=0} \quad$ is the local Nusselt number on the heated wall.

\section{RESULTS AND DISCUSSION}

In this work the numeric results were compared to values obtained by Davis (1983), Hortmann et al. (1990) and Bravo (2000). Numeric meshes made up of 40x40 and $80 \times 80$ control volumes for a Rayleigh number $10^{4}, 10^{5}$ and $10^{6}$ were used.

For each point in the mesh, a residue $R$ can be calculated to indicate the iterative method convergence, in this work $R$ was adopted for residue of the continuity equation (mass conservation), i.e., the convergence criteria was obtained when the highest value of $|R| \leq 10^{-5}$, or better,

$$
\mathrm{R}=\max |\vec{\nabla} \cdot \vec{V}|_{i, j} \leq 10^{-5}
$$

The flow behavior in the computation domain is usually investigated by streamlines. The streamlines are boundaries of constant stream function obtained from the velocity field, defining stream function $\psi$ as,

$$
\frac{\partial \psi}{\partial Y}=U \text { and } \frac{\partial \psi}{\partial X}=-V
$$

Figures 2, 3 and 4 illustrate streamlines (to the left) and isotherms (to the right) from the flow generated by natural convection on the square cavity for the mesh made up of $80 \times 80$ control volumes, for the three investigated Rayleigh numbers, respectively. It is noticed that for $R a=$ $10^{5}$ and $10^{6}$ two small re-circulations are formed near the middle of the cavity. With the growth of the Rayleigh number and, consequently, there is a growth of circulation inside the cavity, more and more a pronounced compression of isotherms near cavity boundaries is observed.
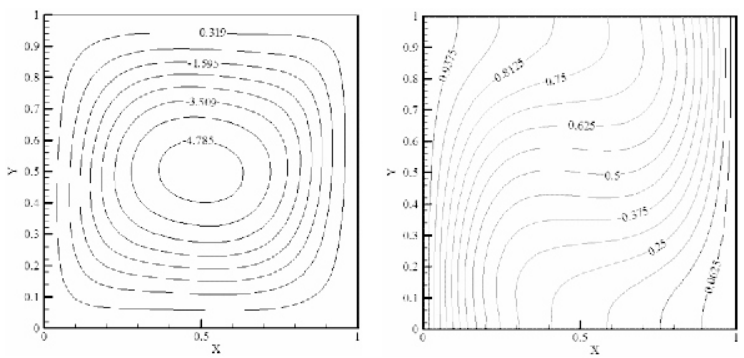

Figure 2. Streamlines (to the left) and isotherms (to the right) for Rayleigh $=10^{4}$
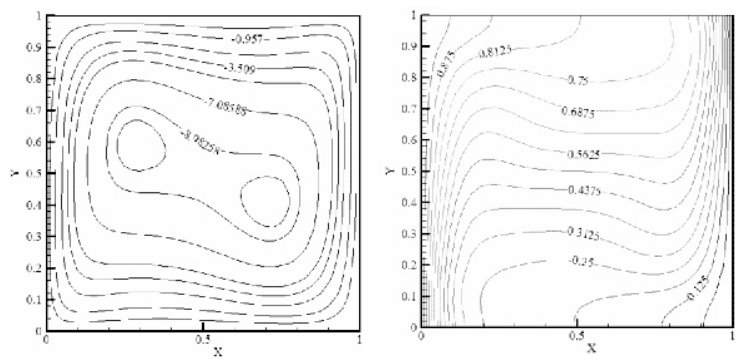

Figure 3. Streamlines (to the left) and isotherms (to the right) for Rayleigh $=10^{5}$
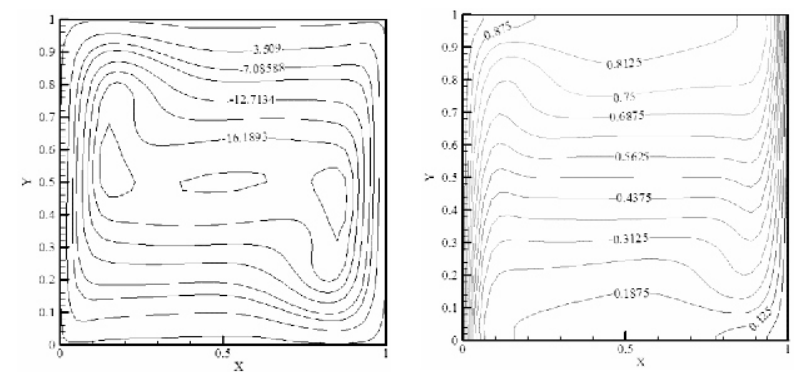

Figure 4. Streamlines (to the left) and isotherms (to the right) for Rayleigh $=10^{6}$

The numeric results from some variables are shown in Tabs. 1, 2 and 3, and those variables are: $\left.\psi\right|_{\max }$ is the maximum stream function modulus; $u_{\max }$ is the maximum horizontal velocity component modulus, $u$, on the cavity central vertical line, at $x=1 / 2 ; v_{\max }$ is the maximum vertical velocity component modulus, $v$, on the cavity central horizontal line, at $y=1 / 2$ and $\overline{N u}$ is the average Nusselt number, according to Eq. 8 .

As seen in Tabs. 1, 2 and 3, the numeric results obtained in this work perform as good as with the results found in the literature for the numeric mesh made up of $40 \times 40$ and $80 \times 80$ control volumes. We can notice that the average Nusselt number is higher for a Rayleigh number equal to $10^{6}$, where the temperature gradients are higher, and so are the velocities for this Rayleigh number, increasing the re-circulation regions. The results of this work are compared to the works of Bravo et al. (2000) who have solved the transient problem, using the Euler method for the discretization of the temporal term and the central difference for discretization on spatial terms, Hortmann et al. (1990) have solved the present problem in a permanent regimen with the finite volume method and Davis (1983) used the implicit method with second rate central differences together with Richardson extrapolation.

The velocity profiles $U$, on the vertical central line, of cavity and velocity $V$, on the horizontal central line of cavity, are shown on Figs. 5 and 6, respectively. On Fig. 5 we notice that there is symmetry on the velocity $U$ profile, comparing to the inferior and superior half of the cavity and on Fig. 6 we notice a slight symmetry when comparing the left and right half of the cavity.

\begin{tabular}{|c|c|c|c|c|c|}
\hline $\begin{array}{r}\text { X } \\
x \\
Y\end{array}$ & $|\psi|_{\max }$ & $U_{\max }$ & $V_{\max }$ & $\overline{N u}$ & References \\
\hline \multirow{4}{*}{$\begin{array}{c}40 \\
\mathrm{x} \\
40\end{array}$} & 5.0855 & 16.1354 & 19.6691 & 2.2469 & $\begin{array}{c}\text { Present } \\
\text { work }\end{array}$ \\
\hline & 5.0917 & 16.0637 & 19.5146 & 2.2492 & Bravo et al. \\
\hline & - & 16.0955 & 19.5303 & 2.2436 & $\begin{array}{c}\text { Hortman et } \\
\text { al. }\end{array}$ \\
\hline & - & 16.182 & 19.5090 & 2.2340 & $\begin{array}{c}\text { De Vahl } \\
\text { Davis }\end{array}$ \\
\hline \multirow{4}{*}{$\begin{array}{c}80 \\
x \\
80\end{array}$} & 5.0764 & 16.1899 & 19.6655 & 2.2419 & $\begin{array}{c}\text { Present } \\
\text { work }\end{array}$ \\
\hline & 5.0077 & 16.1615 & 19.6141 & 2.2470 & Bravo et al. \\
\hline & - & 16.1630 & 19.6082 & 2.2446 & $\begin{array}{c}\text { Hortman et } \\
\text { al. }\end{array}$ \\
\hline & - & - & - & - & $\begin{array}{l}\text { De Vahl } \\
\text { Davis }\end{array}$ \\
\hline
\end{tabular}

Table 1. Numerical results for $\mathrm{Ra}=10^{4}$. 
Table 2. Numerical results for $R a=10^{5}$.

\begin{tabular}{|c|c|c|c|c|c|}
\hline $\begin{array}{l}\mathrm{X} \\
\mathrm{X} \\
\mathrm{Y}\end{array}$ & $|\psi|_{\max }$ & $U_{\max }$ & $V_{\max }$ & $\overline{N u}$ & References \\
\hline \multirow{4}{*}{$\begin{array}{c}40 \\
x \\
40\end{array}$} & 9.7362 & 36.2210 & 68.7922 & 4.6043 & $\begin{array}{c}\text { Present } \\
\text { work }\end{array}$ \\
\hline & 9.7271 & 33.9648 & 67.5619 & 4.5473 & Bravo et al. \\
\hline & - & 34.7396 & 68.8438 & 4.6165 & $\begin{array}{c}\text { Hortman et } \\
\text { al. }\end{array}$ \\
\hline & 9.7390 & 35.0700 & 66.7300 & 4.4870 & $\begin{array}{c}\text { De Vahl } \\
\text { Davis }\end{array}$ \\
\hline \multirow{4}{*}{$\begin{array}{c}80 \\
x \\
80\end{array}$} & 9.6480 & 35.4161 & 68.6208 & 4.5350 & $\begin{array}{c}\text { Present } \\
\text { work }\end{array}$ \\
\hline & 9.6313 & 34.7716 & 68.3291 & 4.5395 & Bravo et al. \\
\hline & - & 34.7132 & 68.5383 & 4.5256 & $\begin{array}{c}\text { Hortman et } \\
\text { al. }\end{array}$ \\
\hline & 9.6440 & 34.8100 & 68.2200 & 4.5100 & $\begin{array}{c}\text { De Vahl } \\
\text { Davis }\end{array}$ \\
\hline
\end{tabular}

Table 3. Numerical results for $R a=10^{6}$.

\begin{tabular}{|c|c|c|c|c|c|}
\hline 4 & $|\psi|_{\max }$ & $U_{\max }$ & $V_{\max }$ & $\overline{N u}$ & Ref. \\
\hline \multirow{4}{*}{$\begin{array}{c}40 \\
x \\
40\end{array}$} & 17.5359 & 67.68371 & 223.1483 & 9.4874 & $\begin{array}{c}\text { Present } \\
\text { work }\end{array}$ \\
\hline & 18.7810 & 63.9505 & 209.7110 & 8.7817 & $\begin{array}{c}\text { Bravo et } \\
\text { al. }\end{array}$ \\
\hline & - & 63.3710 & 223.4120 & 9.4217 & $\begin{array}{c}\text { Hortman } \\
\text { et al. }\end{array}$ \\
\hline & 17.6130 & 67.4900 & 206.3200 & 8.8100 & $\begin{array}{c}\text { De Vahl } \\
\text { Davis }\end{array}$ \\
\hline \multirow{4}{*}{$\begin{array}{c}80 \\
x \\
80\end{array}$} & 17.0268 & 65.6252 & 218.9173 & 8.9752 & $\begin{array}{c}\text { Present } \\
\text { work }\end{array}$ \\
\hline & 16.6521 & 64.0822 & 214.1256 & 8.8410 & $\begin{array}{c}\text { Bravo et } \\
\text { al. }\end{array}$ \\
\hline & - & 64.9944 & 218.3112 & 8.9772 & $\begin{array}{l}\text { Hortman } \\
\text { et al. }\end{array}$ \\
\hline & 16.9610 & 65.3300 & 216.7500 & 8.7980 & $\begin{array}{c}\text { De Vahl } \\
\text { Davis }\end{array}$ \\
\hline
\end{tabular}

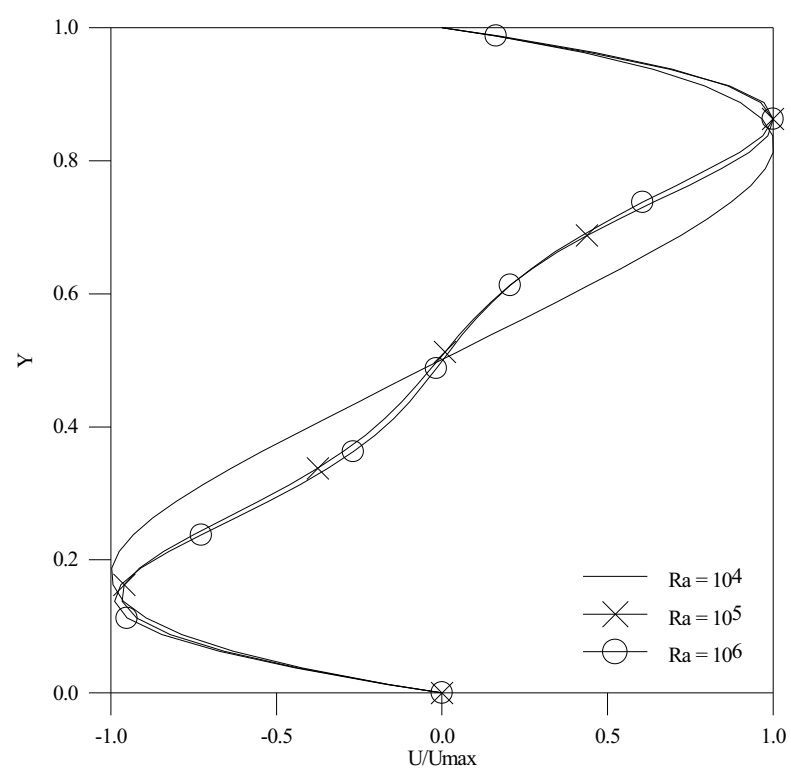

Figure 5. $U / U \max$ velocity profile on the cavity vertical central line for the different Rayleigh numbers

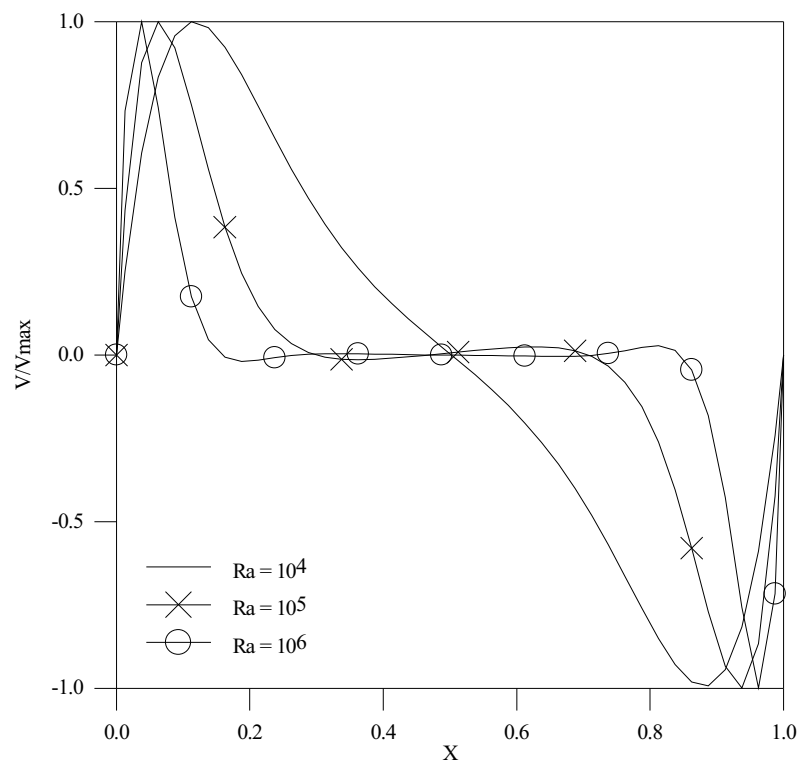

Figure 6. $V / V \max$ velocity profile on the cavity horizontal central line for the different Rayleigh numbers

\section{CONCLUSIONS}

This work has shown a numeric study of thermal and fluid dynamics behavior of natural air convection in a bi-dimensional square cavity, in a laminar flow, where two walls are heated at different temperatures and two walls are isolated, the Boussinesq approximation was used and the Prandtl number was kept stable. The numeric simulations were performed for several Rayleigh numbers, $10^{4} \mathrm{Ra} 10^{6}$, and the results of average Nusselt number were compared with those reported in the literature, converging for the similar solutions. The flow and isotherm lines were shown for different Rayleigh numbers and they were analyzed. The dimensionless velocity profiles $U$ and $V$ on the vertical and horizontal central lines, respectively, were illustrated with the variation of Rayleigh number.

\section{ACKNOWLEDGEMENTS}

The authors would like to acknowledge CAPES for the scholarship provided to the second author of this paper.

\section{REFERENCES}

Aydin, O., Unal, A. and Ayhan, T., 1997, "Numerical Solutions for Buoyancy-Driven Flow in a 2-D Square Enclosure Heated from One Side and Cooled from Above", Proceedings of the Advances in Computational Heat Transfer Symposium, Begell House, New York, pp. 387394.

Bravo, E. O. A., Claeyssen, J. C. and Rubio, O., 2000, "Numerical Simulation for the Natural Convection Flow", Revista de Pesquisa e Pós-Graduação, Erechim, RS, Brasil, 1, pp. 237-254.

Chu, H. H. S., Churchill, S. W. and Patterson, C. V. S., 1976, "The Effect of Heater Size, Location, Aspect Ratio, and Boundary Conditions on Two-Dimensional, Laminar, Natural Convection in Rectangular Channels". Trans. of the ASME J. of Heat Transfer, pp. 194-201.

Corcione, M., 2003, "Effects of the Thermal Boundary Conditions at the Sidewalls Upon Natural Convection in Rectangular Enclosures Heated from Below 
and Cooled from Above", International Journal of Thermal Sciences, 42, pp. 199208.

Davis, G. de V., 1983, "Natural Convection of Air in a Square Cavity: A Benchmark Solution", International Journal for Numerical Methods in Fluids, 3, pp. 249-264.

Ding, H., Shu, C., Yeo, K. S. and Xu, D., 2004, "Development of Least-Square-Based Two-Dimensional Finite-Difference Schemes and their Application to Simulate Natural Convection in a Cavity", Computers \& Fluids, 33, pp. 137-154.

Doescher, E., Velho, H. F. de C. and Ramos, F. M., 2003, "Isothermal and Natural Convection Flows in Fractal Cavities", Applied Numerical Mathematics, 47, pp. 407419.

Hortmann, M., Peric, M. and Scheuerer, G., 1990, "Finite Volume multigrid prediction of laminar natural convection: benchmark solutions", International Journal for Numerical Methods in Fluids, 11, pp. 189-207.

Le Quéré, P., 1991, “Accurate Solutions to the Square Thermally Driven Cavity at High Rayleigh Number", Computers \& Fluids, 20, pp. 29-41.

Maliska, C. R., 1995, "Transferência de Calor e Mecânica dos Fluidos Computacional - Fundamentos e Coordenadas Generalizadas", LTC, Rio de Janeiro, 424 p.

Oh, J. Y., Ha, M. Y. and Kim, K. C., 1997, "Numerical Study of Heat Transfer and Flow of Natural Convection in an Enclosure with a Heat-Generating Conduction Body", Numerical Heat Transfer, Part A, 31, pp. 289-303.

Ostrach, S., 1988, "Natural Convection in Enclosures", Journal Heat Transfer, 110, pp. 1175-1190.

Patankar, S. V., 1980, "Numerical Heat Transfer and Fluid Flow", Hemisphere Washington, DC, 197, 197 p.

Peng, Y., Shu, C. and Chew, Y. T., 2003, "A 3D Incompressible Thermal Lattice Boltzmann Model and its Application to Simulate Natural Convection in a Cubic Cavity", Journal of Computational Physics, 193, pp. 260274.

Reinehr, E. L., Ulson de Souza, A. A. and Guellli U. S., S. M. A., 2000, "Solução do Escoamento Hidrodinâmico em Ambientes Confinados com Convecção Mista", Anais do VIII Encontro Brasileiro de Ciências Térmicas e Engenharia, Porto Alegre, pp. 1-10. 